\title{
Influence of ageing, inclusions and voids on ductile fracture mechanism in commercial Al-alloys
}

\author{
A CHENNAKESAVA REDDY* and S SUNDAR RAJAN ${ }^{\dagger}$ \\ Department of Mechanical Engineering, JNTU College of Engineering, Kukatpally, Hyderabad 500 072, India \\ ${ }^{\dagger}$ Defence R\&D Laboratories, Kanchanbagh, Hyderabad 500 058, India
}

MS received 20 July 2004; revised 14 September 2004

\begin{abstract}
The objective of the paper is to study the effect of ageing, inclusions and voids on the mechanism of fracture and resultant toughness. It has been found that the voids are initiated at only a fraction of the larger inclusions present. The initiation of voids at small particles in the ductile fracture process appears to have little effect on fracture toughness. The strain hardening capacity has a marked effect on void size, and is an indicator of fracture toughness in the commercial Al alloy.
\end{abstract}

Keywords. Ageing; inclusions; voids; ductile fracture; Al-alloy.

\section{Introduction}

Increase in strength on ageing of aluminium alloys is usually accompanied by a corresponding decrease in toughness (Kanninen and Popelar 1985). It is found that under-aged conditions show considerably superior toughness compared with over-aged conditions of the same yield strength. In commercial $\mathrm{Al}-\mathrm{Zn}-\mathrm{Mg}$ alloys this has been associated with a change in fracture mode from predominantly transgranular in the under-aged state to intergranular in the over-aged condition (Kirman 1971).

It is important to establish the significance of inclusions or second-phase particles on the fracture mechanism in commercial Al alloys. The relatively low fracture toughness of the high strength aluminium alloys is a significant limitation to their commercial application, and considerable research has been carried out to examine the metallurgical factors affecting intercrystalline weakness and the role of second-phase inclusion particles (Ashby et al 1979). It is the objective of this paper to study the influence of inclusions, voids and state of ageing on the mechanism of fracture and the fracture toughness.

\section{Experimental}

The commercial alloy used in the investigation is BS L65 having a composition (wt $\%) 4.28 \% \mathrm{Cu}, 0.67 \% \mathrm{Mg}, 0.72 \%$ $\mathrm{Mn}, 0.83 \% \mathrm{Si}, 0.33 \% \mathrm{Fe}, 0.14 \% \mathrm{Zn}$ and $0.05 \%$ inclusions, balance Al. Specimens were cut from rolled plate and solution treated $\left(500^{\circ} \mathrm{C}\right)$ and quenched into water at room temperature, prior to ageing, typically carried out at $190^{\circ} \mathrm{C}$, for times chosen to give a range of yield strengths.

*Author for correspondence (dr_acreddy@yahoo.com)
Three different parameters of toughness were used, viz. $K_{\mathrm{IC}}, K_{\mathrm{c}}^{*}$ (mixed-mode) and unit propagation energy (UPE). Fracture toughness results were obtained from fatigue pre-cracked $6.35 \mathrm{~mm}$ thick compact specimens (CTS) as shown in figure 1 (British Standard). The tear test was adopted in order to provide a relative toughness measurement. Machined notched specimens were pulled to failure; fracture was assumed to initiate at the maximum load, and the area under the load/displacement curve after initiation was taken to represent the energy required propagating the crack. This energy divided by the transverse section area was used as the toughness parameter, UPE.

\section{Results and discussion}

Figure 2 shows the variation of yield stress with ageing time illustrating the general trend. Figure 3 shows the variation of toughness with ageing time. The toughness decreases with increasing ageing time. The specimens of under-aged treatments have superior toughness compared with those of over-aged treatments of the same yield strength. It is also significant to note that increasing fracture toughness in Al-alloy is associated with an increased capacity for strain hardening, as measured by the exponent, $n$ (figure 4).

\subsection{Second-phase inclusions}

In commercial $\mathrm{Al}$ alloys there is a wide range of inclusion particles present that can act as sites for void nucleation (figure 5), and they are found to exist in two regimes of size (figure 5b). Both the larger inclusions $\sim 1-10 \mu \mathrm{m}$ diameter, and the smaller ones (dispersoids) $\sim 0-1 \mu \mathrm{m}$ 
diameter, are formed during casting. Typically they are $\mathrm{Fe}-, \mathrm{Mn}-, \mathrm{Mg}$ - and Si-rich particles.

\subsection{Nucleation and growth of voids}

Figure 6 shows the initiation of voids at inclusions. The voids can be initiated primarily as a result of cleavage fracture of the large particles at very low strains $(\sim 3 \%)$. 40 to $50 \%$ of the larger particles are cracked after $7 \%$ of plastic strain. As for the large particles, they rupture or decohere producing small, closely spaced dimples on the

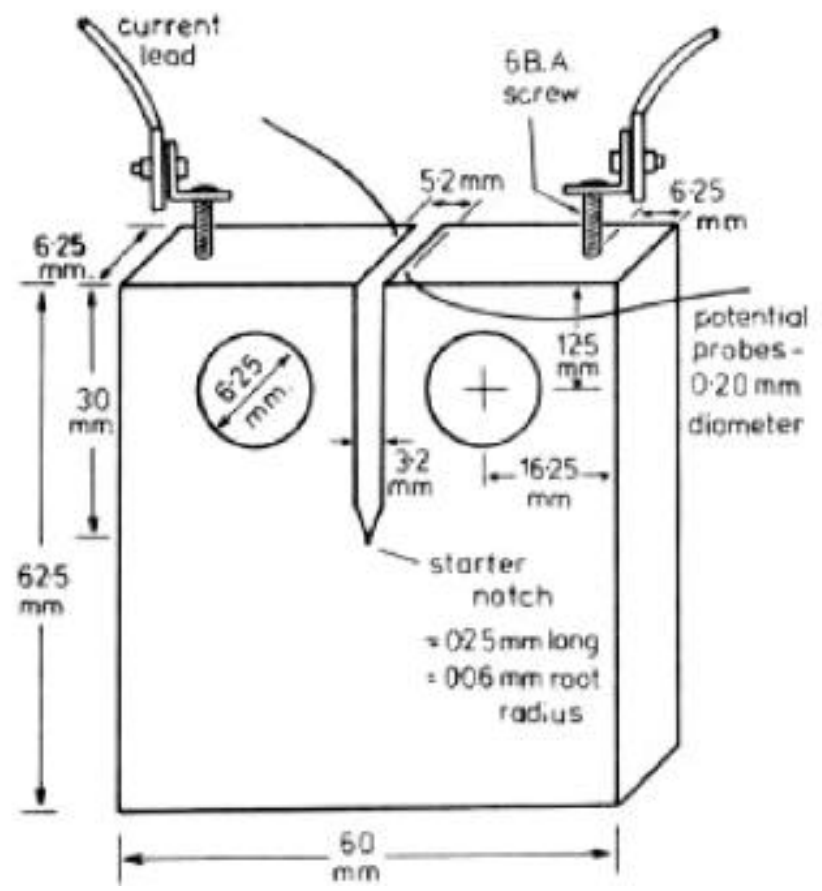

Figure 1. CTS specimen design with electrical potential lead arrangements for fatigue crack monitoring and fracture toughness tests.

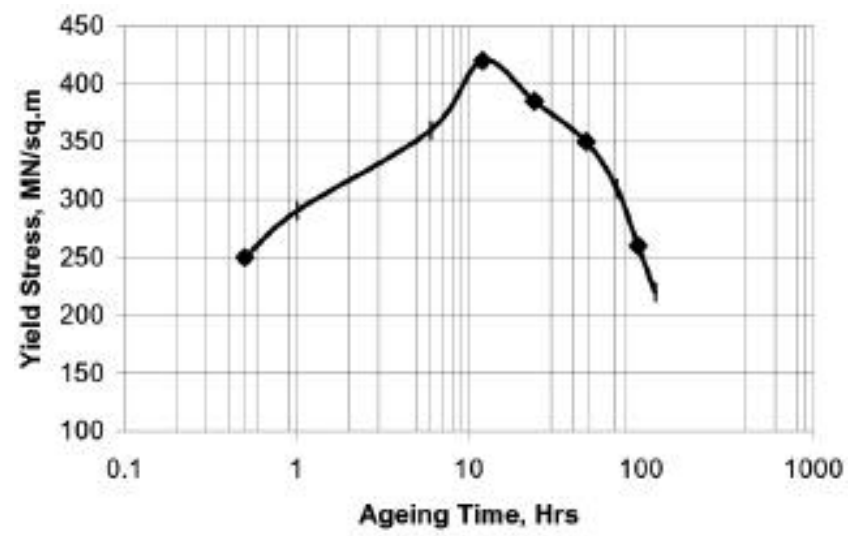

Figure 2. The influence of ageing time on yield stress. final fracture surface. Hahn and Rosenfield (1975) contend that virtually all the large particles in commercial Al alloys are cracked by the time they enter the region of intense plastic strain at the tip of a crack in view of the greater interface stresses. This implies that the smaller inclusions fail only late in the fracture process when plastic deformation is localized and concentrated. Van Stone and Psioda (1975) suggested that the final stage in the fracture process is the coalescence of voids initiated at large particles by a mechanism of void sheet formation consisting of submicron dimples initiated at the $\sim 0-1 \mu \mathrm{m}$ dispersoid particles by interface decohesion.

Recognizing that voids at large inclusions can form at very low strains, Hahn and Rosenfield (1975) developed a model of ductile failure based on the concept that the critical step in the fracture process is the extension of cracking between cracked particles, or void growth. They utilized an approximate failure criterion proposed by Rice and Johnson (1970), i.e. that crack extension proceeds when the extent of the zone of intense plastic strain at a crack tip is comparable to the width of the unbroken

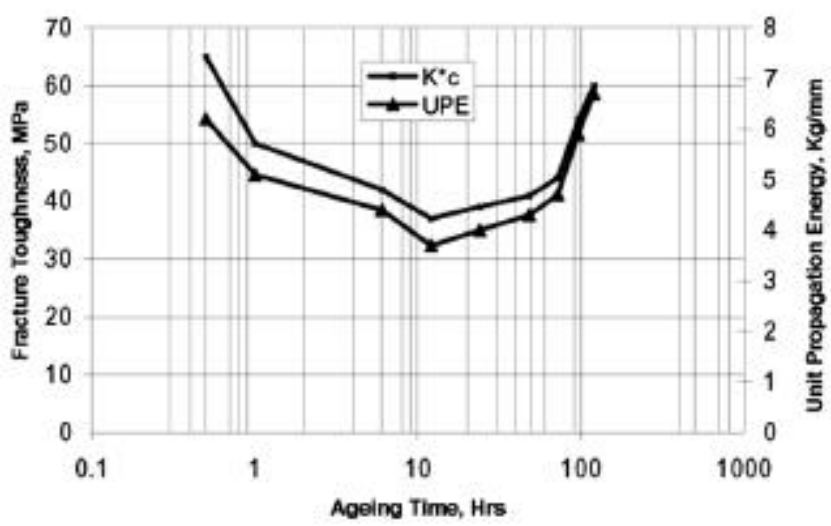

Figure 3. Effect of ageing on the fracture toughness and unit propagation energy.

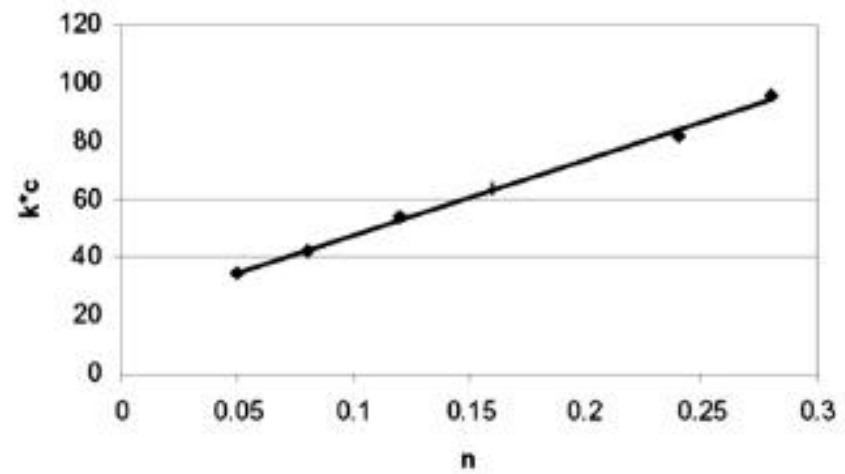

Figure 4. Variation of fracture toughness with strain hardening exponent, $n$, obtained from $\sigma=\sigma_{0} \varepsilon_{\mathrm{p}}^{n}$, where $\varepsilon_{\mathrm{p}}$ is the true strain at plastic instability. 

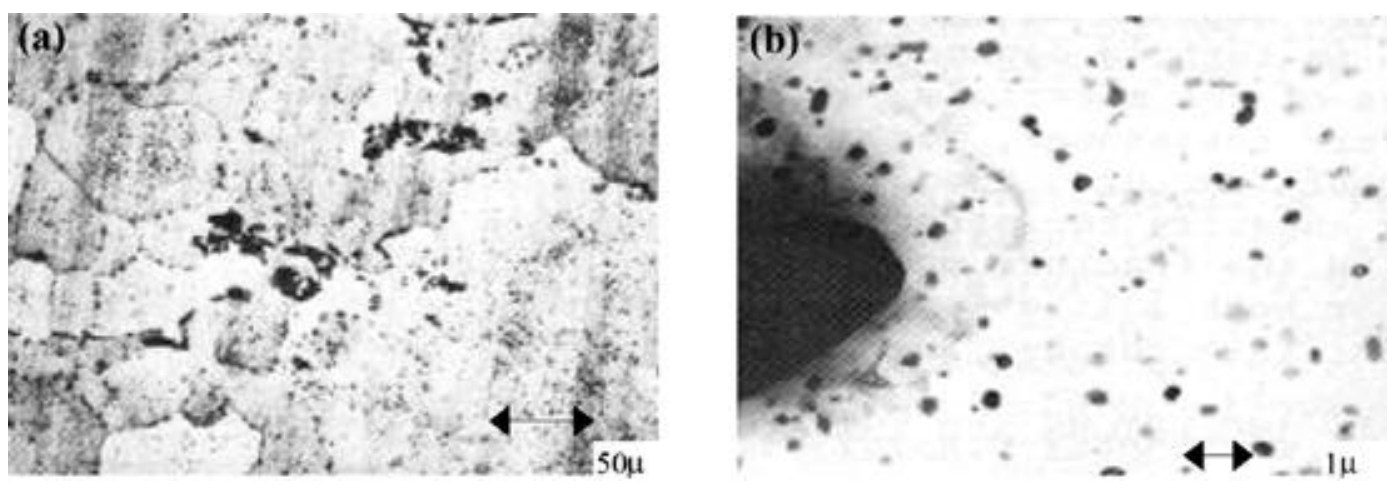

Figure 5. Second-phase inclusion distribution in the commercial Al alloy: (a) optical micrograph and (b) transmission electron micrograph.

ligaments separating cracked particles. This leads to a solution for the fracture toughness, of the form

$$
K_{\mathrm{IC}}=\left[2 \sigma_{\mathrm{y}} E(\pi / 6)^{1 / 3} D\right]^{1 / 2} V_{\mathrm{f}}^{-1 / 6}
$$

where $\sigma_{\mathrm{y}}$ and $E$ are respectively the yield strength and elastic modulus and $V_{\mathrm{f}}$ the volume fraction of the larger inclusions of average diameter, $D$.

Although there appears to be good experimental agreement between $K_{\mathrm{IC}}$ and $V_{\mathrm{f}}^{-1 / 6}$, certain other implications of this equation throw some doubt on its validity, and therefore, on the assumptions on which it is based.

Firstly, as admitted by Hahn and Rosenfield (1975), the relation predicts an increase rather than a decrease in fracture toughness with increasing yield strength at a constant volume fraction and distribution of the larger inclusions (figure 6).

Secondly, as noted by Van Stone and Psioda (1975), toughness does not increase with increasing size, $D$, of void nucleating particles, as illustrated by the experiments of Cox and Low (1974). These researchers found that the stress necessary for void initiation by cracking at inclusions is inversely proportional to the square root of the average inclusion diameter, $D$. They observed that by comparing steels of the same yield strength and essentially identical inclusion spacing, the smaller inclusion size resulted in a substantial increase in toughness.

Finally, calculations based on quantitative measurements for a range of age-hardened $\mathrm{Al}$ alloys (having yield strengths in excess of $400 \mathrm{MPa}$ and $K_{\mathrm{IC}}$ values in the range $20-30 \mathrm{MNm}^{-3 / 2}$ ) provide support for the assumptions (Rice and Johnson 1970) used in deriving (1) in that they indicate reasonable agreement between the extent of the region of intense plastic strain at a crack tip and the ligament spacing, i.e. the spacing between cracked particles as evaluated by the average dimple size. Thus, voids are initiated at only a fraction of the larger inclusions, as observed by Burghard (1974), suggesting that in the early stages of plastic deformation the growth of existing voids (initiated at certain large particles, $\sim 5 \mu \mathrm{m}$ diameter) is

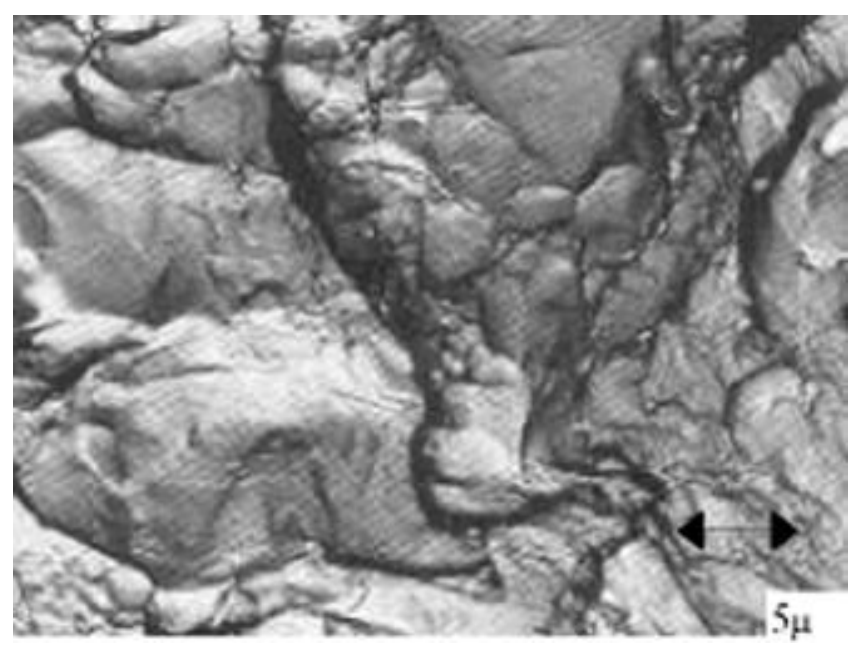

Figure 6. Transmission electron micrograph showing the range of dimple sizes present arising from void initiation at inclusions and subsequent growth and coalescence.

favoured over the initiation of new voids at other large particles present within the intense plastic zone at the crack tip.

Figures $7 \mathrm{a}-\mathrm{d}$ illustrate the typical unidirectional fractures (from fracture toughness specimens) of the Al alloy for a range of ageing conditions. It is apparent that the fracture appearance associated with the peak-aged, lowest toughness condition is characterized by small, shallow voids formed round the larger inclusions. As the toughness increases the voids initiated at the same type of inclusions become deeper and more widely spaced. These results may be related to the variation of the plastic deformation characteristics of the matrix associated with ageing. For the peak aged condition, where work hardening is low, the deformation which occurs between large inclusions remains localized and the growth of voids from adjacent particles limits the final dimple size to a value approximating to the average inter-particle spacing, as observed by Burghard (1974) as well as in the present investigation. 
As more strain hardening occurs, deformation spreads over a large volume, and the average size of the voids increases (Cabot and Burlion 1996). Voids that initiate at particular inclusions can grow to a uniform size considerably in excess of the average particle spacing without the interference of adjacent particles, or the initiation of additional voids at these adjacent particles.

\subsection{Void coalescence and the effect of small inclusions}

It has been stated (Van Stone and Psioda 1975) that a reduction in dispersoid size may reduce the stresses acting on the dispersoid and permit more void growth by delaying the formation of void sheets resulting in higher toughness. Figure 8a shows the resulting fracture surface appearance of the commercial alloy heat treated to produce over-aged, incoherent precipitate particles, themselves capable of initiating voids. There may be a certain critical size at which ageing precipitates become big enough to produce voids. For the commercial alloy under study this occurs at an ageing time of $10 \mathrm{~min}$ at $350^{\circ} \mathrm{C}$. What is evident from the resulting fracture morphology (figure $8 b$ ) is the large number of smaller dimples initiated under these conditions. These observations indicate that small voids can form from the small inclusions during the stage when plastic deformation is localized i.e. during the growth of voids formed from larger inclusions, rather than as any separate, critical event in itself.

The real influence of the size spectrum of non-metallic inclusions is on the deformation characteristics of the matrix itself, via their influence on the slip process. As suggested by Hawk et al (1988), higher plastic deformation and ductility result owing to a dislocation climbing process over the intermetallic dispersoids $\left(\mathrm{Al}_{15} \mathrm{Mn}_{3} \mathrm{Si}_{2}\right)$. Thus figure 9a illustrates dislocation tangling around the smaller inclusion particles. Such interactions affect the matrix deformation behaviour resulting in an increased flow stress but decreased capacity for strain hardening. In addition, the smaller inclusions can markedly affect the
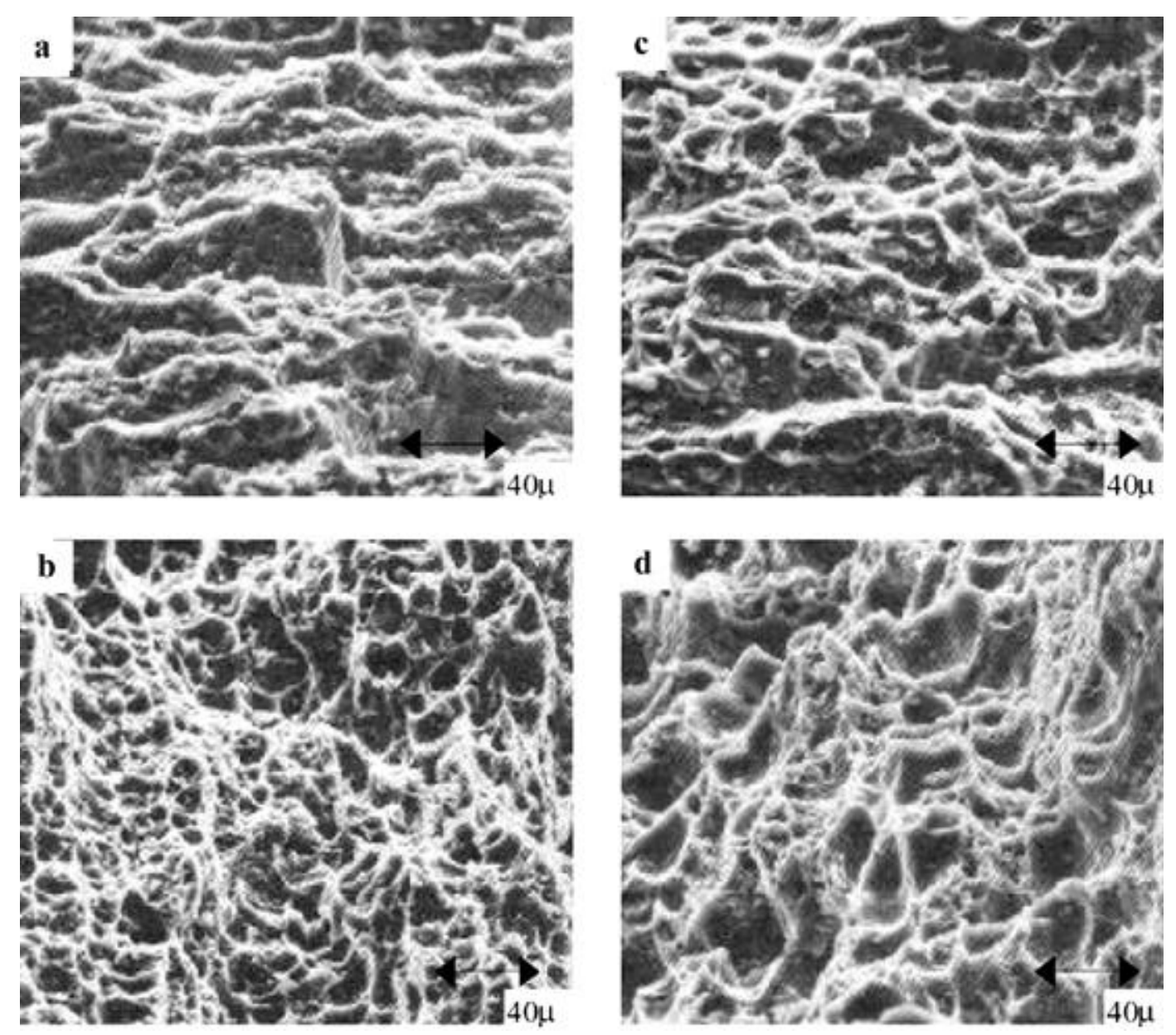

Figure 7. The influence of ageing on voids growth: (a) peak-aged condition, $12 \mathrm{~h}$, (b) over-aged condition, $72 \mathrm{~h}$, (c) over-aged condition, $96 \mathrm{~h}$ and (d) over-aged condition, $120 \mathrm{~h}$. Toughness increases in the order $\mathbf{a} \rightarrow \mathbf{b} \rightarrow \mathbf{c} \rightarrow \mathbf{d}$. The voids produced change from being small and shallow to much larger and deeper. 

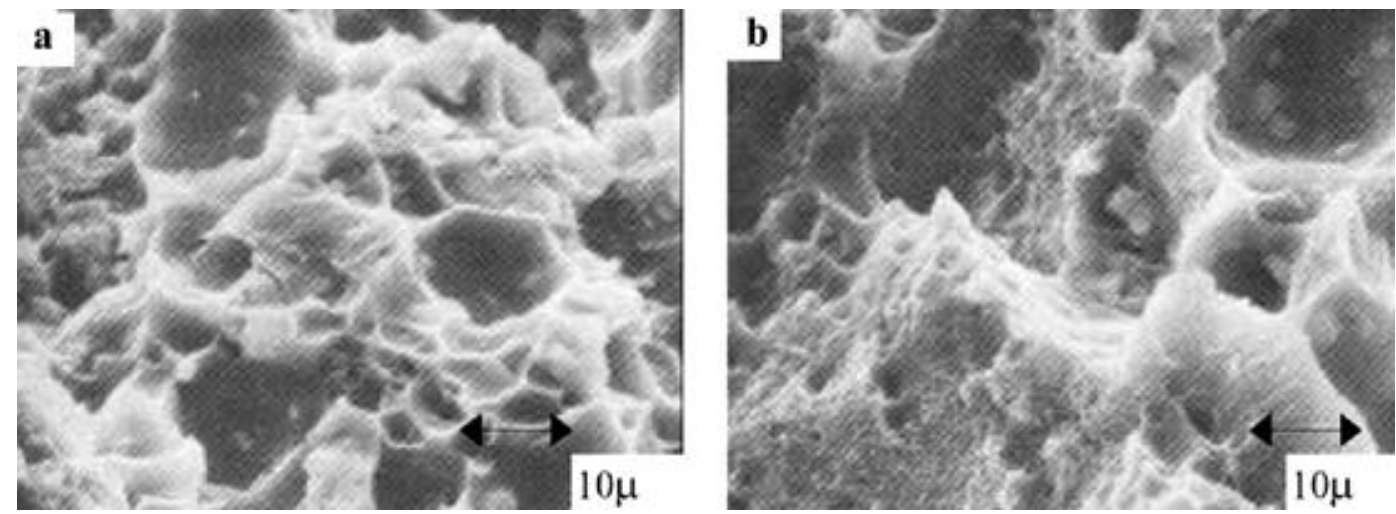

Figure 8. Increase in number of small voids present nucleated at equilibrium precipitate particles: (a) under-aged condition and (b) over-aged condition.
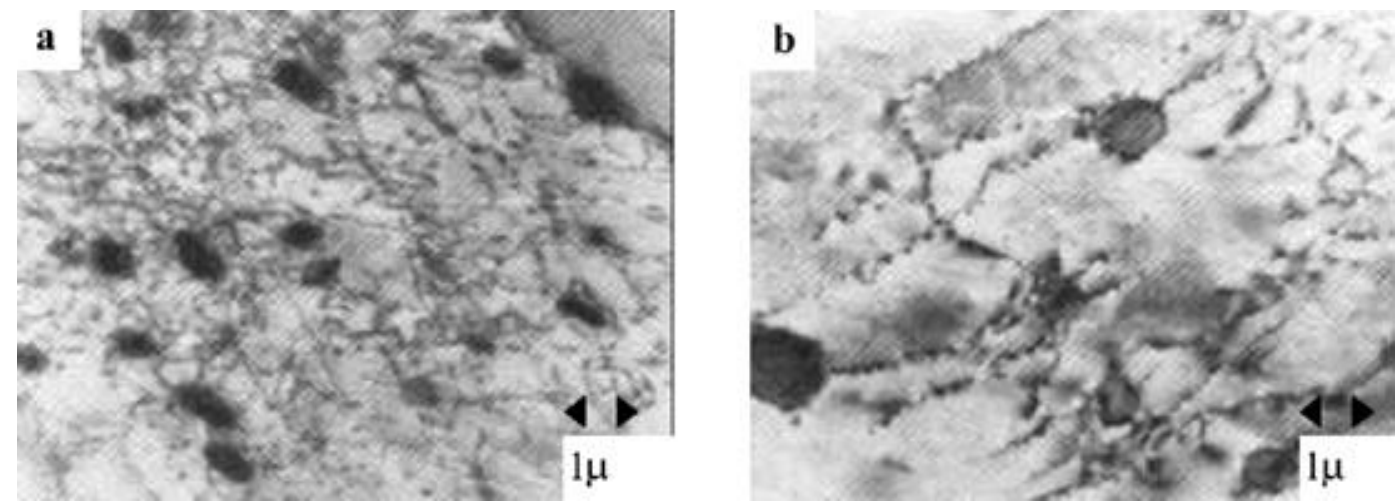

Figure 9. The effect of small inclusions or dispersoids on (a) dislocation and interactions and (b) precipitation on dislocations trapped between inclusions during quenching.

homogeneity of precipitate distribution (figure $9 \mathrm{~b}$ ), in turn affecting the deformation process.

\section{Conclusions}

The under-aged alloys show a superior toughness compared with over-aged conditions of the same yield strength because of their improved capacity to accommodate strain prior to the onset of fracture.

In commercial $\mathrm{Al}$ alloy this trend is accompanied by an increase in the average size of voids produced during the fracture process. Thus, depending on the deformation characteristics of the matrix, voids, which subsequently grow, are initiated at only a fraction of the larger inclusions present.

The initiation of voids at small particles during the coalescence stage in the ductile fracture process appears to have little effect on the fracture toughness.

\section{References}

Ashby M F, Gandhi C and Taplin D M R 1979 Acta Metal. 27 699

British Standard, B.S. DD3, Fracture Toughness Testing

Burghard R C 1974 Met. Trans. 52083

Cabot G and Burlion N 1996 J. Mech. Cohesive-Frictional Mater. 1129

Cox T B and Low J R 1974 Met. Trans. 5459

Hahn G T and Rosenfield A R 1975 Met. Trans. $A 6653$

Hawk J A, Angers L M and Wilsdorf H G F 1988 Dispersion strengthened aluminium alloys (PA, USA: TMS) p. 337

Kanninen M F and Popelar C H 1985 Advanced fracture mechanics (UK: Oxford University Press)

Kirman I 1971 Metall. Trans. 21761

Rice J R and Johnson M A 1970 Inelastic behaviour of materials (New York: McGraw-Hill) p. 641

Van Stone R H and Psioda J A 1975 Met.Trans. A6 668 